\title{
ERRy target genes are poor prognostic factors in Tamoxifen-treated breast cancer
}

\author{
Subha Madhavan, Yuriy Gusev, Salendra Singh and Rebecca B Riggins*
}

\begin{abstract}
Background: One-third of estrogen (ER+) and/or progesterone receptor-positive (PGR+) breast tumors treated with Tamoxifen (TAM) do not respond to initial treatment, and the remaining $70 \%$ are at risk to relapse in the future. Estrogen-related receptor gamma (ESRRG, ERRY) is an orphan nuclear receptor with broad, structural similarities to classical ER that is widely implicated in the transcriptional regulation of energy homeostasis. We have previously demonstrated that ERRY induces resistance to TAM in ER+ breast cancer models, and that the receptor's transcriptional activity is modified by activation of the ERK/MAPK pathway. We hypothesize that hyper-activation or over-expression of ERRY induces a pro-survival transcriptional program that impairs the ability of TAM to inhibit the growth of ER+ breast cancer. The goal of the present study is to determine whether ERRY target genes are associated with reduced distant metastasis-free survival (DMFS) in ER+ breast cancer treated with TAM.

Methods: Raw gene expression data was obtained from 3 publicly available breast cancer clinical studies of women with ER+ breast cancer who received TAM as their sole endocrine therapy. ERRY target genes were selected from 2 studies that published validated chromatin immunoprecipitation (ChIP) analyses of ERRY promoter occupancy. Kaplan-Meier estimation was used to determine the association of ERRY target genes with DMFS, and selected genes were validated in ER+, MCF7 breast cancer cells that express exogenous ERRY.

Results: Thirty-seven validated receptor target genes were statistically significantly altered in women who experienced a DM within 5 years, and could classify several independent studies into poor vs. good DMFS. Two genes (EEF1A2 and PPIF) could similarly separate ER+, TAM-treated breast tumors by DMFS, and their protein levels were measured in an ER+ breast cancer cell line model with exogenous ERRY. Finally, expression of ERRY and these two target genes are elevated in models of ER+ breast cancer with hyperactivation of ERK/MAPK.
\end{abstract}

Conclusions: ERRY signaling is associated with poor DMFS in ER+, TAM-treated breast cancer, and ESRRG, EEF1A2, and PPIF comprise a 3-gene signaling node that may contribute to TAM resistance in the context of an active ERK/MAPK pathway.

Keywords: Estrogen-related receptor gamma, Tamoxifen, ER+ breast cancer, MAPK, Apoptosis

\section{Background}

With an estimated 1.38 million new cases diagnosed annually, breast cancer is a global public health challenge [1]. Endocrine therapy administered as an antiestrogen, such as Tamoxifen (TAM) or Fulvestrant, or an aromatase inhibitor (AI), such as Letrozole, Anastrozole, or Exemestane, is the least toxic and most effective means by which to manage hormone-dependent breast cancers. TAM increases overall survival from invasive breast cancer,

\footnotetext{
*Correspondence: rbr7@georgetown.edu

Department of Oncology, Lombardi Comprehensive Cancer Center,

Georgetown University Medical Center, Washington DC 20057, USA
}

reduces the incidence of estrogen receptor- $\alpha$ positive (ER + ) disease in high-risk women, and can reduce the rate of postmenopausal osteoporotic bone loss [2,3]. It remains the standard of care for pre-menopausal breast cancer. When compared to adjuvant TAM in post-menopausal women, AIs alone or in sequence with TAM show significantly improved disease-free survival [4,5], while only letrozole provides a corresponding improvement in overall survival [6]. Thus, the optimal endocrine therapy regimen - and appropriate length of treatment - remains controversial for post-menopausal women.

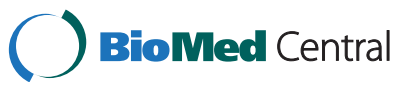

(c) 2015 Madhavan et al.; licensee BioMed Central. This is an Open Access article distributed under the terms of the Creative Commons Attribution License (http://creativecommons.org/licenses/by/4.0), which permits unrestricted use, distribution, and reproduction in any medium, provided the original work is properly credited. The Creative Commons Public Domain Dedication waiver (http://creativecommons.org/publicdomain/zero/1.0/) applies to the data made available in this article, unless otherwise stated. 
Whichever way these controversies are resolved, both AIs and TAM will remain as key modalities in the management of ER+ breast cancers. Unfortunately, the inability of endocrine therapies to cure many women with ER+ disease will also remain. For example, one-third of $\mathrm{ER}+$ /progesterone receptor-positive $(\mathrm{PGR}+)$ breast tumors treated with TAM do not respond to initial treatment, and the remaining $70 \%$ are at risk to relapse in the future $[7,8]$. The development of resistance to AIs is also clearly documented [9-12]. A number of mechanisms have been proposed to regulate antiestrogen or TAM resistance in ER+ breast cancer, including changes in the expression or activity of genes and proteins that regulate tumor cell survival $[13,14]$. These tend to fall into 3 broad categories: genes that are (or can be) direct transcriptional targets of ER (e.g. PGR, CCND1, MYC); genes that are co-regulators which directly bind to ER or act on ER to modify its function (e.g. AKT, MAPK, AIB1, XBP1), and genes that can also act functionally independent of the estrogen receptor (e.g. BCAR1, BCAR3, IRF1). The identification of microRNA [15] and long non-coding RNA [16] signatures with prognostic power in ER+ breast cancers has further enhanced our understanding of receptor-driven signaling.

Estrogen-related receptor gamma (ESRRG, ERRY) is an orphan nuclear receptor with broad, structural similarities to classical ER that is widely implicated in the transcriptional regulation of energy homeostasis [17]; in breast cancer, ERRY is preferentially expressed in ER+ disease [18]. We have previously published that $a$. ERR $\gamma$ is upregulated during the acquisition of Tamoxifen (TAM) resistance by ER+ breast cancer cells and $b$. overexpression of ERR $\gamma$ is sufficient to induce TAM resistance [19], and c. ERRy's transcriptional activity and ability to induce TAM resistance is enhanced by activation of the ERK/MAPK pathway [20]. ERR $\gamma$ overexpression also induces proliferation in ER+ breast cancer cells in the presence or absence of estrogen [21], and cooperates with cytoplasmic proline, glutamic acid and leucine rich protein 1 (PELP1) to inhibit TAM-mediated death in normal human mammary epithelial cells [22]. Interestingly expression of ESRRG is also significantly associated with a reduction in pathologic complete response (pCR) in locally advanced breast tumors treated with chemotherapy [23]. Our central hypothesis is that hyperactivation or over-expression of ERR $\gamma$ induces a prosurvival transcriptional program that impairs the ability of TAM to inhibit the growth of ER+ breast cancer.

One of the barriers faced in addressing this hypothesis is translating data from laboratory/cell line studies into meaningful observations in breast cancer clinical data. For example, in one clinical study we found that ERRY mRNA is significantly overexpressed in surgical (i.e. pretreatment) $\mathrm{ER}+$ breast tumor specimens from women who relapsed while receiving TAM [24], but this result is either not observed or not statistically significant in several other publicly available datasets of TAM-treated, ER + breast cancer patients. Chang et al. [25] reported similar challenges in correlating mRNA expression of family member ERR $\alpha$ with poor outcome in breast cancer clinical specimens, but successfully generated a reproducible measure of ERR $\alpha$ activity in vivo by monitoring the expression of receptor target genes. We therefore examined the expression of validated ERR $\gamma$ target genes in publicly available ER+ breast cancer datasets as a proxy for receptor activity rather than expression, which we propose is similarly a more relevant measure of in vivo ERR $\gamma$ function in endocrine therapy response and resistance.

\section{Methods}

\section{ERRY target gene selection}

Genes were selected from two independent studies in which chromatin immunoprecipitation (ChIP) for ERR $\gamma$ was performed, and target genes were subsequently validated. Dufour et al. [26] performed high-throughput ChIP-on-chip on wild type adult mouse heart tissues, while Eichner et al. [27] analyzed ERR $\gamma$ chromatin binding by conventional ChIP in BT-474 human breast cancer cells.

\section{Clinical datasets, gene expression analyses and functional annotation}

Raw data from three publicly available datasets containing ER+ breast tumor surgical specimens were downloaded from Gene Expression Omnibus: Loi et al. GSE6532 and GSE91915, [28]; Zhou et al. GSE7378, [29]; and Zhang, GSE12093, [30]. Data processing pipelines in G-DOC [31] were used to obtain lists of differentially expressed genes (DEGs; fold change $\geq 1.5$ and uncorrected $\mathrm{p} \leq 0.05$ ) from all datasets as described in [32].

\section{Cell culture, expression constructs, transfection, western blot analysis, and cell line datasets}

MCF7 cells were originally provided by Marvin Rich (Karmanos Cancer Institute, Detroit, MI, USA), and cultured in improved minimal essential media (IMEM) supplemented with $5 \%$ fetal bovine serum (FBS). The pSG5 plasmid vector with cDNA insert encoding wild type, hemagglutinin (HA)-tagged murine ERR $(100 \%$ identical to human ERR $\gamma$ ) has been described previously $[19,20,33]$. MCF7 cells were transiently transfected with HA-ERRY or pSG5 empty vector for $27 \mathrm{~h}$ using JetPrime (VWR, Radnor, PA, USA) prior to whole cell lysis, polyacrylamide gel electrophoresis, protein transfer to nitrocellulose membranes, immunoblotting, and chemiluminescent detection performed as described in [20,34]. Primary antibodies used were: anti-HA.11 clone $16 \mathrm{~B} 12$ at 1:500 (Covance, Princeton, NJ, USA); anti-EEF1A2 SAB2100650 
Table 1 Sources of ERR $\boldsymbol{y}$ target genes

\begin{tabular}{lllll}
\hline Study [Reference] & Study type & Species & Tissue & \# ERR $\boldsymbol{\gamma}$ targets \\
\hline Dufour et al. [26] & $\begin{array}{l}\text { ChIP-on- } \\
\text { chip }\end{array}$ & mouse & adult heart & 231 validated \\
Eichner et al. [27] & $\begin{array}{l}\text { Standard } \\
\text { ChIP }\end{array}$ & human & $\begin{array}{l}\text { BT-474 human } \\
\text { breast cancer } \\
\text { cell line }\end{array}$ & \\
\hline
\end{tabular}

at 1:500 (Sigma, St. Louis, MO, USA); and anti-PPIF SAB4500035 at 1:500 (Sigma). Membranes were reprobed for $\beta$-actin (Sigma, 1:10,000) as a loading control. NIH ImageJ (http://rsbweb.nih.gov/ij/) was used for densitometric analysis of ERR $\gamma$ (HA), EEF1A2, and PPIF expression relative to $\beta$-actin. Levels of ESRRG, EEF1A2, and PPIF mRNA in MCF7 and BT-474 cell line samples published in [35,36] were obtained from ONCOMINE [37].

\section{Statistical analysis}

The KM Plotter Tool (http://kmplot.com/analysis/) [38] was used to calculate hazard ratios, confidence intervals, and log-rank $P$ values for the aggregated breast cancer clinical studies. All other statistical analyses were performed in GraphPad Prism 5.0c for Mac (GraphPad Software, Inc., La Jolla, CA, USA) using the Mantel-Cox log-rank test, $\chi^{2}$ test, or Mann Whitney rank sum test, as indicated. Statistical significance is defined as $P \leq 0.05$.

\section{Results and discussion}

\section{Identification of ERR $\gamma$ target genes}

ERR $\gamma$ can stimulate transcription from multiple DNA response elements: the palindromic estrogen response element (ERE), a half site known as the estrogen-related receptor response element (ERRE) which it shares with other orphan nuclear receptors (e.g. steroidogenic factor 1 response element, SF1RE), and indirectly through either the activator protein 1 (AP1) (reviewed in [24]) or the specificity protein 1 (SP1) response element [39]. In addition, Deblois et al. identified the hybrid element ERRE/ERE as the major binding site for another member of the estrogen-related receptor family $(E R R \alpha)$ in breast cancer [40], which we have recently demonstrated can also be regulated by ERR $\gamma$ [20]. However, the most comprehensive collection of validated ERR $\gamma$ transcriptional targets comes from two independent, published studies in which high-throughput chromatin immunoprecipitation

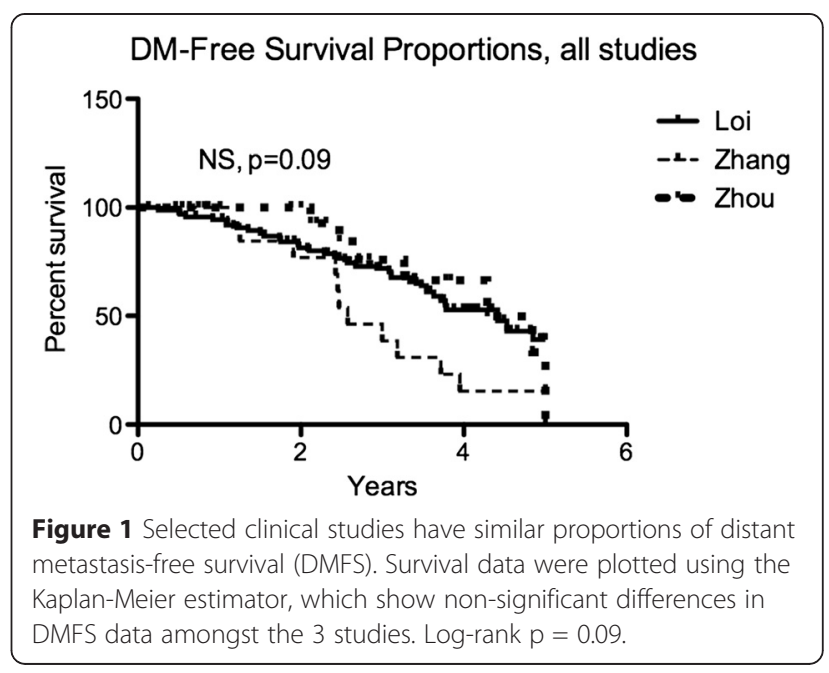

(ChIP-on-chip), or standard ChIP, data were obtained for ERR $\gamma$ binding to the ERRE half site in promoters/upstream regulatory regions (Table 1). Gene IDs identified in [26] were converted from Mus musculus to Homo sapiens nomenclature using Pathway Studio, then merged with those from [27].

We used the Georgetown Database of Cancer (GDOC, [31]) to examine the expression of these ERR $\gamma$ target genes in TAM-resistant and -responsive human breast tumors from three independent clinical datasets (Table 2). Data are derived from ER+ breast tumor specimens collected at the time of surgery, prior to initiation of TAM therapy. We selected these three datasets because they a) are primarily comprised of ER+ breast cancer patients who received TAM as their only systemic therapy (with the exception of 18 patients in Zhou), b) utilize compatible expression array platforms, and $c$ ) have sufficient length of follow-up to perform a meaningful comparison between those patients with documented distant metastasis $\leq 5$ years (Event, 5yrE) and those with no distant metastasis $\leq 5$ years (Censored, $5 y r C)$. All 3 studies have similar overall distant metastasis (DM)-free survival proportions (Figure 1). We also, where available, examined 3 clinical parameters that could introduce bias into our results, because each has independently been shown to be a prognostic factor for DM [41]: age, lymph node status, and primary tumor size. While primary tumor size is not significantly different between groups, patients in the 5yrE group (documented

Table 2 Breast cancer datasets

\begin{tabular}{|c|c|c|c|c|}
\hline Study [Reference] & Study type & Sample type & Array platform(s) & GSE accession \# \\
\hline Loi et al. [28] & Microarray & Surgical specimen & U133A, B, Plus 2.0 & GSE6532 \\
\hline Loi et al. [28] & Microarray & Surgical specimen & U133A, B, Plus 2.0 & GSE9195 \\
\hline Zhou et al. [29] & Microarray & Surgical specimen & U133A & GSE7378 \\
\hline Zhang et al. [30] & Microarray & Surgical specimen & U133A & GSE12093 \\
\hline
\end{tabular}


DM) are significantly younger (Mann Whitney rank sum test, $\mathrm{p}<0.01$ ) and more likely to be lymph node-positive $\left(\chi^{2}, \mathrm{p}<0.0001\right)$ than those in the $5 y \mathrm{yr}$ group (no documented DM within 5 years).

\section{ERR $y$ target genes in TAM-resistant breast tumors}

We next identified statistically significant, differentially expressed genes (DEGs; fold change $\geq 1.5$ and uncorrected $p \leq 0.05)$ in the 5yrE group for each of the studies, and overlaid these lists with those of the validated ERR $\gamma$ targets. Then, to ensure that these ERR $\gamma$ targets were predictive of TAM-resistant distant metastasis rather than simply poor prognostic factors, we excluded from the list genes that showed the same regulation (direction of fold change) in an independent dataset of $\mathrm{ER}+$, lymph node-negative breast cancer patients from (GSE7390, [42]) who received no systemic therapy. This resulted in a final list of 37 DEGs (32 up-regulated, 5 down-regulated; Table 3). Using the KM Plotter Tool (http://kmplot.com/analysis/) [38], we showed that these 37 DEGs (alone or with the addition of ESRRG) serve as a molecular signature that is significantly associated with poor distant metastasis-free survival (DMFS) in 504 women with ER+ breast cancer treated with TAM monotherapy (Figure $2 \mathrm{~A}, \mathrm{HR}=1.75, \mathrm{p}=0.0065$ ). By contrast, these 37 DEGs show the opposite association (i.e. with improved DMFS) in 53 women with ER- breast cancer treated with chemotherapy (Figure $2 \mathrm{~B}, \mathrm{HR}=0.35$, $\mathrm{p}=0.024)$.

ERR $\gamma$ target gene functional annotation and validation Using Gene Set Enrichment Analysis tools in Pathway Studio, the Molecular Signatures Database (MSigDB, [43]), and WebGestalt [44], we examined the ERRY gene signature for commonalities in Gene Ontology and functional annotations. Given that ERR $\gamma$ and its family members promote mitochondrial biogenesis and control the transcription of nearly all essential enzymes of the oxidative phosphorylation pathway [17], it is not surprising that many genes associated with respiratory oxidative phosphorylation $(\mathrm{p}=0.00024)$ and the electron transport chain ( $\mathrm{p}=2.18 \mathrm{E}-13$ ) are significantly overrepresented. However, other functional categories highly relevant to the TAM-resistant phenotype are also enriched, including apoptosis $(\mathrm{p}=0.027)$, protein folding $(\mathrm{p}=0.0023)$ and mitochondrial protein transport $(\mathrm{p}=5.88 \mathrm{E}-05)$. Two novel and particularly interesting ERR $\gamma$ target genes in this regard are eukaryotic elongation factor 1A2 (EEF1A2), a putative oncogene and elongation factor that delivers tRNAs to active ribosomes, and peptidylprolyl isomerase factor $\mathrm{F}$ (PPIF, more commonly known as Cyclophilin D), a key component of the mitochondrial protein folding machinery and the inner membrane permeability transition pore. EEF1A2 strongly promotes cancer cell proliferation and
Table 337 DEGs significantly associated with distant metastasis (DM) in ER+, TAM-treated patients

\begin{tabular}{|c|c|c|c|}
\hline Analysis: & DMFS $\leq 5$ & nsor vs. Ev & \\
\hline Treatment: & TAM & TAM & TAM+ \\
\hline Patient \#: & 95 vs. 68 & 3 vs. 11 & 17 vs 7 \\
\hline Gene & Loi & Zhang & Zhou \\
\hline$\overline{A C A D M}$ & & up & \\
\hline AHSA1 & up & & up \\
\hline $\mathrm{ARIH} 2$ & & & up \\
\hline ATP5C1 & & up & \\
\hline ATP5F1 & & up & \\
\hline CENPT & & & up \\
\hline CSMD1 & down & & \\
\hline DLST & & & up \\
\hline EEF1A2 & & & up \\
\hline ETFB & up & & \\
\hline GTPBP4 & & up & \\
\hline HSPA9 & up & & \\
\hline IDH1 & & up & \\
\hline MED23 & & & up \\
\hline MYCN & down & & \\
\hline NADK & up & & up \\
\hline NDUFA8 & & up & \\
\hline NDUFB5 & & up & \\
\hline NDUFS1 & & up & \\
\hline NDUFS7 & up & & \\
\hline ORMDL1 & up & & \\
\hline PAN2 & & & up \\
\hline PCMTD2 & & & up \\
\hline PPIF & & up & \\
\hline PTCD3 & & & up \\
\hline PTPN18 & & down & \\
\hline RAB11B & & down & \\
\hline RAB21 & & up & up \\
\hline RARA & down & & \\
\hline SDHD & & up & \\
\hline SLC35E2 & & & up \\
\hline SPTLC2 & up & & \\
\hline SUCLA2 & & up & \\
\hline TIMM17A & & up & \\
\hline TRRAP & & & up \\
\hline TSPAN8 & & & up \\
\hline UNC50 & & up & \\
\hline
\end{tabular}

Legend: italicized, also present in prognostic list, but opposite regulation; bold, present in $>1$ dataset. 

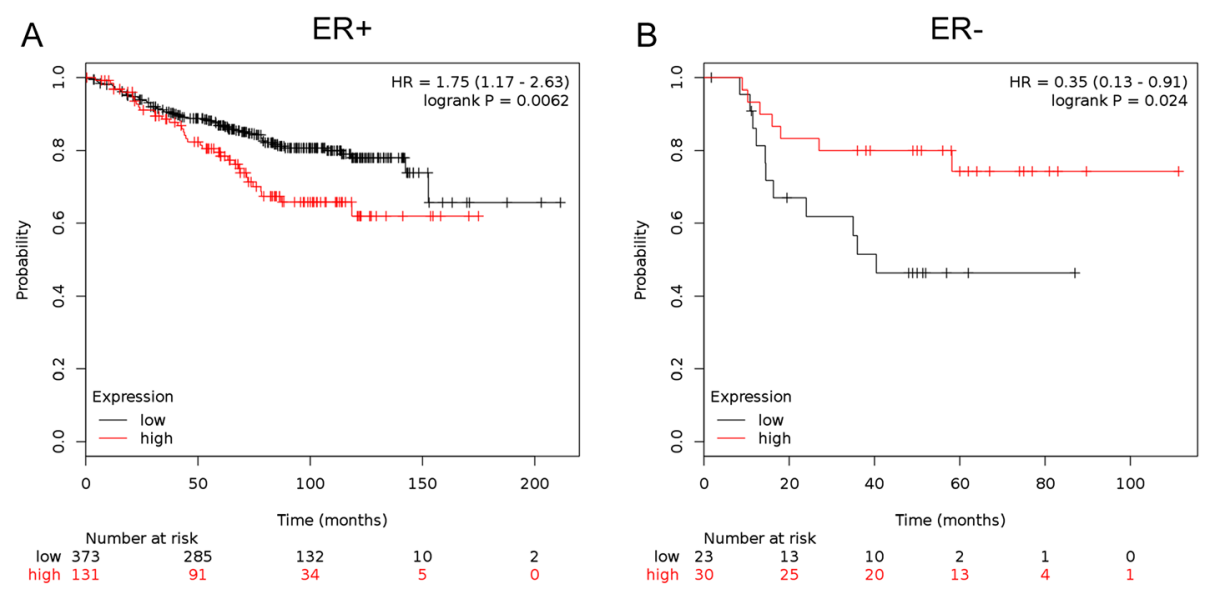

Figure 2 ERRy and its target genes predict poor DMFS in ER+, but not ER-, breast cancer. Gene symbols for 35 of the 37 ERR target DEGs (2 were not annotated) were entered into KM Plotter and used to classify DMFS data from women with ER+, TAM-treated breast cancer $(\mathbf{A}, n=504, H R=$ $1.75, \log$-rank $p=0.006)$ or ER-, chemotherapy-treated breast cancer $(\mathbf{B}, n=53, H R=0.35$, log-rank $p=0.024)$.

resistance to apoptosis in several malignancies [45-47]. The role of PPIF in apoptosis is less clear; many studies describe a pro-death role for PPIF and the mitochondrial permeability transition pore in general, while others [48] show that PPIF can suppress apoptosis induced by exogenous stimuli such as TNF, UV radiation, or arsenic trioxide, possibly through negative regulatory interactions with Bcl-2 [49,50]. In addition, a three-gene signature comprised of ERR $\gamma$, EEF1A2, and PPIF alone is significantly associated with poor distant metastasis-free survival (DMFS) in the same 504 women with ER+ breast cancer who received Tamoxifen monotherapy (Figure 3A, HR = 1.57, $\mathrm{p}=0.022$ ). To validate EEF1A2 and PPIF as target genes of ERRY in ER+ breast cancer, we measured their protein expression in MCF7 cells transiently transfected with ERR $\gamma$, which we [20] and others [21] have shown induces Tamoxifen resistance and estrogen-independent growth, respectively (Figure $3 \mathrm{~B}$ ). While PPIF is not induced, EEF1A2 protein is $\sim 1.5$-fold increased in cells transfected with ERR $\gamma$ relative to the $\beta$-actin loading control.

We have recently shown that regulation of ERR $\gamma$ protein by ERK/MAPK enhances the receptor's transcriptional activity and is required for its ability to induce Tamoxifen resistance in ER+ breast cancer cells [20,51]. However, the relationship between ERK/MAPK and either ERR $\gamma$ or EEF1A2 at the mRNA level has not been characterized. We therefore examined their message levels in gene expression microarray data from ER+ MCF7
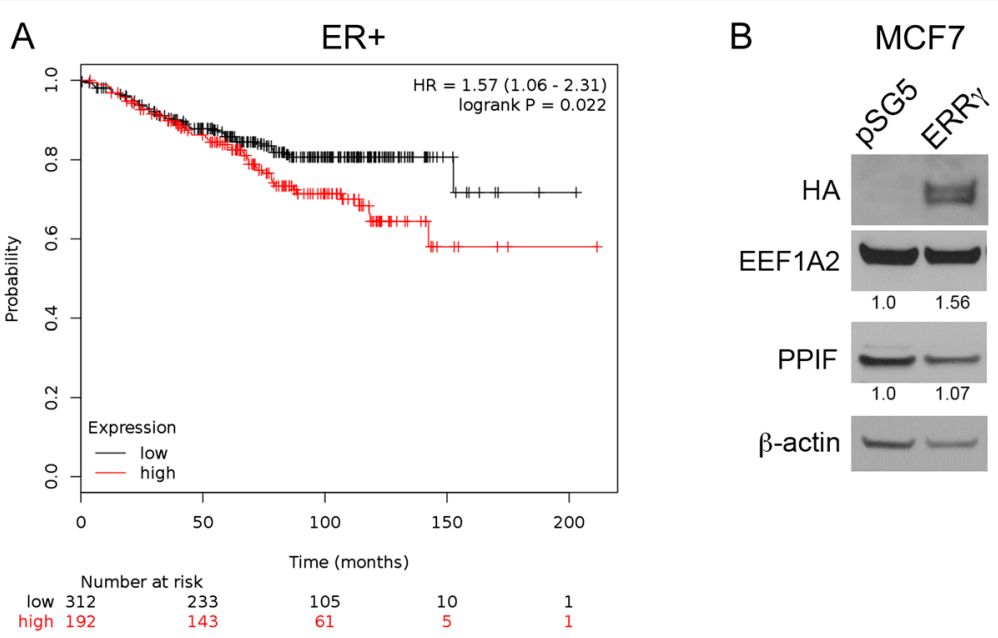

Figure 3 Predictive value and expression of ERRy target genes EEF1A2 and PPIF in ER+ breast cancer. A, The 3-gene signature of ESRRG, EEF1A2, and PPIF predicts poor DMFS in ER+, TAM-treated breast cancer using KM Plotter ( $n=504, H R=1.57$, log-rank $p=0.022$ ). $\mathbf{B}$, Expression of EEF1A2 and PPIF protein in MCF7 cells transiently expressing exogenous hemagglutinin (HA-) tagged ERRY. $\beta$-actin serves as the loading control. Relative expression of EEF1A2 (1.57) and PPIF (1.07) in ERRY-transfected cells vs. empty vector control (1.0) was analyzed using NIH Image J. 

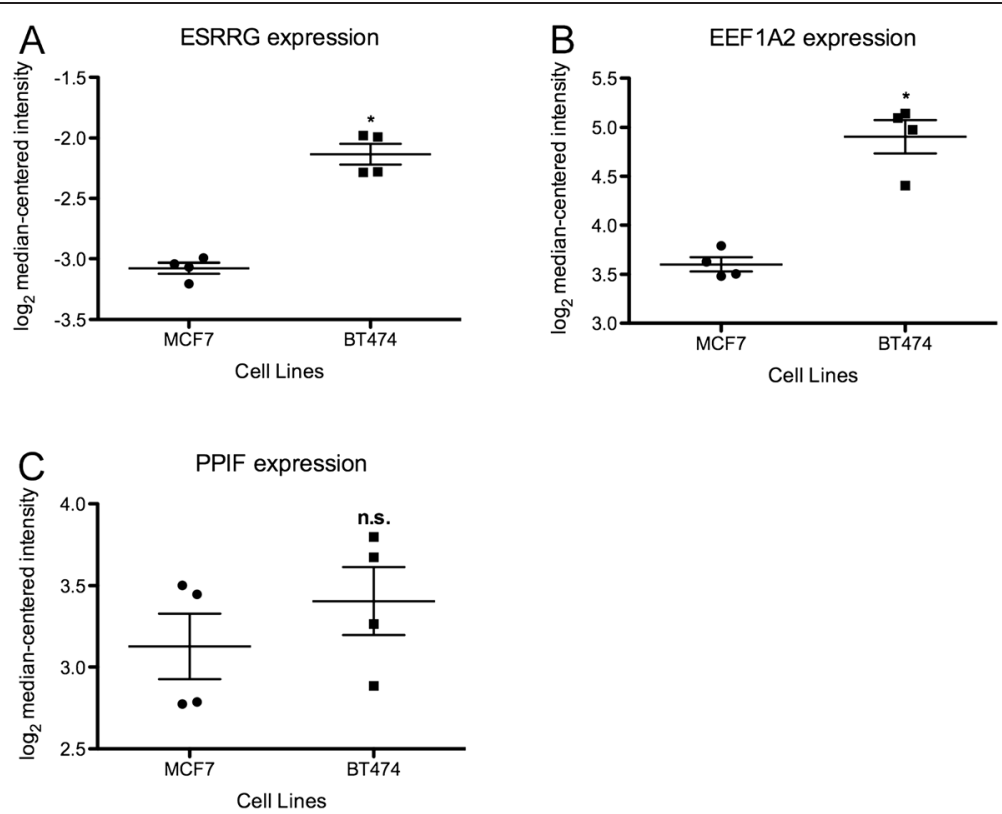

Figure 4 Expression of ESRRG, EEF1A2, and PPIF correlates with ERK/MAPK activation status in ER+ breast cancer cells. Gene expression data from Rae et al. obtained from ONCOMINE were analyzed for ESRRG (A), EEF1A2 (B), and PPIF (C) in $n=3$ replicates per cell line. Mann Whitney rank-sum $p<0.05\left(^{*}\right)$.

and BT474 breast cancer cells [35], the latter well known for overexpression of HER2 and hyperactivation of the ERK/MAPK pathway. Expression of ESRRG (Figure 4A) and EEF1A2 (Figure 4B), but not PPIF (Figure 4C), is significantly higher in BT474 cells. Interestingly in a second dataset [36], EEF1A2 expression is markedly and significantly induced in ER+ MCF7 breast cancer cells in which either MEK (4.01-fold increase, $\mathrm{p}=0.027)$ or HER2 (3.34fold increase, $\mathrm{p}=0.036$ ) has been exogenously expressed vs. the empty vector control. PPIF is also modestly induced (MEK: 1.38-fold increase, $\mathrm{p}=0.01$; HER2: 1.27-fold increase, $\mathrm{p}=0.007$ ).

\section{Conclusions}

The goal of the present study was to determine whether ERRY target genes are associated with reduced DMFS in ER+ breast cancer treated with Tamoxifen. Our findings suggest that i. ERRY signaling is associated with poor DMFS in ER+, TAM-treated breast cancer, and ii. ESRRG, EEF1A2, and PPIF comprise a 3-gene signaling node that may contribute to Tamoxifen resistance in the context of an active ERK/MAPK pathway.

\section{Abbreviations}

TAM: Tamoxifen; Al: Aromatase inhibitor; ER+: Estrogen receptor-positive; PGR+: Progesterone receptor-positive; CCND1: Cyclin D1; MAPK: Mitogenactivated protein kinase; AIB1: Amplified in breast cancer 1; XBP1: X-box binding protein 1; BCAR1: Breast cancer antiestrogen resistance 1; BCAR3: Breast cancer antiestrogen resistance 3; IRF1: Interferon regulatory factor 1; ESRRG or ERRY: Estrogen-related receptor gamma; ERK: Extracellular signal-regulated kinase; ChIP: Chromatin immunoprecipitation; HA: Hemagglutinin; EEF1A2: Eukaryotic elongation factor 1A2; PPIF: Peptidylprolyl isomerase factor F;
KM: Kaplan-Meier; ERE: Estrogen response element; ERRE: Estrogen-related response element; AP1: Activator protein 1; SP1: Specificity protein 1; G-DOC: Georgetown Database of Cancer; $5 y$ rE: Event at 5 years; $5 y r C$ : Censored at 5 years; DM: Distant metastasis; DEGs: Differentially expressed genes; DMFS: Distant metastasis-free survival; HR: Hazard ratio; MSigDB: Molecular Signatures Database; TNF: Tumor necrosis factor; HER2: Human epidermal growth factor receptor 2 .

\section{Competing interests}

The authors declare that they have no competing interests.

\section{Authors' contributions}

SM contributed to the study design and obtained funding. YG and SS analyzed data. RBR designed the study and obtained funding, performed the in silico and wet-lab experiments, and wrote the manuscript. All authors contributed significantly to the editing of the manuscript. All authors read and approved the final manuscript.

\section{Acknowledgements}

These studies were supported by a Career Catalyst Research Grant from Susan G. Komen for the Cure (KG090187, Principal Investigator R.B.R), start-up funds to R.B.R from the Lombardi Comprehensive Cancer Center (LCCC) Support Grant (P30 CA51008, Principal Investigator Dr. Louis M. Weiner), U54 CA149147 (Principal Investigator Dr. Robert Clarke), and HHSN2612200800001E (co-Program Directors Drs. Robert Clarke and Subha Madhavan). Technical services were provided by the LCCC Genomics \& Epigenomics and Tissue Culture Shared Resources, which are also supported in part by P30 CA51008. The content of this article is solely the responsibility of the authors and does not necessarily represent the official views of the National Cancer Institute, the National Institutes of Health, or Susan G. Komen for the Cure.

Received: 3 December 2014 Accepted: 26 March 2015

Published online: 15 May 2015

\section{References}

1. Jemal A, Bray F, Center MM, Ferlay J, Ward E, Forman D. Global cancer statistics. CA Cancer J Clin. 2011;61(2):69-90.

2. Ebctcg: Early Breast Cancer Trialists' Collaborative Group. Tamoxifen for early breast cancer: an overview of the randomized trials. Lancet. 1998;351:1451-67. 
3. Ebctcg: Early Breast Cancer Trialists Collaborative Group. Systemic treatment of early breast cancer by hormonal, cytotoxic, or immune therapy. Lancet. 1992;399:1-15

4. Coombes RC, Hall E, Gibson LJ, Paridaens R, Jassem J, Delozier T, et al. A randomized trial of exemestane after two to three years of tamoxifen therapy in postmenopausal women with primary breast cancer 1. N Engl J Med. 2004;350(11):1081-92.

5. Thurlimann B, Keshaviah A, Coates AS, Mouridsen H, Mauriac L, Forbes JF, et al. A comparison of letrozole and tamoxifen in postmenopausal women with early breast cancer. N Engl J Med. 2005;353(26):2747-57.

6. Schiavon G, Smith IE. Status of adjuvant endocrine therapy for breast cancer. Breast Cancer Res. 2014;16(2):206.

7. Davies C, Godwin J, Gray R, Clarke M, Cutter D, Darby S, et al. Relevance of breast cancer hormone receptors and other factors to the efficacy of adjuvant tamoxifen: patient-level meta-analysis of randomised trials. Lancet. 2011;378(9793):771-84

8. Riggins R, Bouton AH, Liu MC, Clarke R. Antiestrogens, aromatase inhibitors, and apoptosis in breast cancer. Vitam Horm. 2005;71:201-37.

9. Frogne T, Benjaminsen RV, Sonne-Hansen K, Sorensen BS, Nexo E, Laenkholm AV, et al. Activation of ErbB3, EGFR and Erk is essential for growth of human breast cancer cell lines with acquired resistance to fulvestrant. Breast Cancer ResTreat. 2008;114:263-75.

10. Macedo LF, Sabnis G, Brodie A. Preclinical modeling of endocrine response and resistance: focus on aromatase inhibitors. Cancer. 2008;112(3 Suppl):679-88.

11. Macedo L, Sabnis G, Brodie A. Aromatase inhibitors and breast cancer. Ann N Y Acad Sci. 2009;1155:162-73.

12. Rechoum $Y$, Rovito D, lacopetta D, Barone I, Andò S, Weigel NL, et al. AR collaborates with ERa in aromatase inhibitor-resistant breast cancer. Breast Cancer Res Treat. 2014;147(3):473-85.

13. Clarke R, Shajahan AN, Riggins RB, Cho Y, Crawford A, Xuan J, et al. Gene network signaling in hormone responsiveness modifies apoptosis and autophagy in breast cancer cells. J Steroid Biochem Mol Biol. 2009;114(1-2):8-20.

14. Riggins RB, Schrecengost RS, Guerrero MS, Bouton AH. Pathways to tamoxifen resistance. Cancer Lett. 2007;256(1):1-24.

15. Zhou X, Wang X, Huang Z, Xu L, Zhu W, Liu P. An ER-associated miRNA signature predicts prognosis in ER-positive breast cancer. J Exp Clin Cancer Res. 2014;33(1):94.

16. Meng J, Li P, Zhang Q, Yang Z, Fu S. A four-long non-coding RNA signature in predicting breast cancer survival. J Exp Clin Cancer Res. 2014;33(1):84.

17. Giguere V. Transcriptional control of energy homeostasis by the estrogenrelated receptors. Endocr Rev. 2008;29(6):677-96.

18. Ariazi EA, Clark GM, Mertz JE. Estrogen-related receptor alpha and estrogenrelated receptor gamma associate with unfavorable and favorable biomarkers, respectively, in human breast cancer. Cancer Res. 2002;62(22):6510-8.

19. Riggins RB, Lan JP, Zhu Y, Klimach U, Zwart A, Cavalli LR, et al. ERR\{gamma\} Mediates tamoxifen resistance in novel models of invasive lobular breast cancer. Cancer Res. 2008;68(21):8908-17.

20. Heckler MM, Thakor H, Schafer CC, Riggins RB. ERK/MAPK regulates ERRY expression, transcriptional activity and receptor-mediated tamoxifen resistance in ER+ breast cancer. FEBS J. 2014;281(10):2431-42.

21. Ijichi N, Shigekawa T, Ikeda K, Horie-Inoue K, Fujimura T, Tsuda H, et al. Estrogen-related receptor $\gamma$ modulates cell proliferation and estrogen signaling in breast cancer. J Steroid Biochem Mol Biol. 2011;123(1-2):1-7.

22. Girard BJ, Regan Anderson TM, Welch SL, Nicely J, Seewaldt VL, Ostrander JH. Cytoplasmic PELP1 and ERRgamma protect human mammary epithelial cells from tam-induced cell death. PLoS One. 2015;10(3):e0121206.

23. Gianni L, Zambetti M, Clark K, Baker J, Cronin M, Wu J, et al. Gene expression profiles in paraffin-embedded core biopsy tissue predict response to chemotherapy in women with locally advanced breast cancer. J Clin Oncol. 2005;23(29):7265-77.

24. Riggins RB, Mazzotta MM, Maniya OZ, Clarke R. Orphan nuclear receptors in breast cancer pathogenesis and therapeutic response. Endocr Relat Cancer. 2010;17(3):R213-31.

25. Chang CY, Kazmin D, Jasper JS, Kunder R, Zuercher WJ, McDonnell DP. The metabolic regulator ERRa, a downstream target of HER2/IGF-1R, as a therapeutic target in breast cancer. Cancer Cell. 2011;20(4):500-10.

26. Dufour CR, Wilson BJ, Huss JM, Kelly DP, Alaynick WA, Downes M, et al. Genome-wide orchestration of cardiac functions by the orphan nuclear receptors ERRalpha and gamma. Cell Metab. 2007;5(5):345-56.
27. Eichner $\amalg$, Perry MC, Dufour CR, Bertos N, Park M, St-Pierre J, et al. miR-378(*) mediates metabolic shift in breast cancer cells via the PGC-1ß/ERRY transcriptional pathway. Cell Metab. 2010;12(4):352-61.

28. Loi S, Haibe-Kains B, Desmedt C, Wirapati P, Lallemand F, Tutt AM, et al. Predicting prognosis using molecular profiling in estrogen receptor-positive breast cancer treated with tamoxifen. BMC Genomics. 2008;9:239.

29. Zhou Y, Yau C, Gray JW, Chew K, Dairkee SH, Moore DH, et al. Enhanced NF kappa B and AP-1 transcriptional activity associated with antiestrogen resistant breast cancer. BMC Cancer. 2007;7:59.

30. Zhang Y, Sieuwerts AM, McGreevy M, Casey G, Cufer T, Paradiso A, et al. The 76-gene signature defines high-risk patients that benefit from adjuvant tamoxifen therapy. Breast Cancer Res Treat. 2009;116(2):303-9.

31. Madhavan S, Gusev Y, Harris M, Tanenbaum DM, Gauba R, Bhuvaneshwar K, et al. G-DOC: a systems medicine platform for personalized oncology. Neoplasia. 2011;13(9):771-83.

32. Gusev Y, Riggins RB, Bhuvaneshwar K, Gauba R, Sheahan L, Clarke R, et al. In silico discovery of mitosis regulation networks associated with early distant metastases in estrogen receptor positive breast cancers. Cancer Inform. 2013;12:31-51.

33. Hong H, Yang L, Stallcup MR. Hormone-independent transcriptional activation and coactivator binding by novel orphan nuclear receptor ERR3 1. J Biol Chem. 1999;274(32):22618-26.

34. Bouker KB, Skaar TC, Fernandez DR, O'Brien KA, Clarke R. Interferon regulatory factor-1 mediates the proapoptotic but not cell cycle arrest effects of the steroidal antiestrogen ICI 182,780 (Faslodex, Fulvestrant). Cancer Res. 2004;64(11):4030-9.

35. Rae JM, Johnson MD, Scheys JO, Cordero KE, Larios JM, Lippman ME. GREB 1 is a critical regulator of hormone dependent breast cancer growth. Breast Cancer Res Treat. 2005;92(2):141-9.

36. Creighton CJ, Hilger AM, Murthy S, Rae JM, Chinnaiyan AM, El-Ashry D. Activation of mitogen-activated protein kinase in estrogen receptor alpha-positive breast cancer cells in vitro induces an in vivo molecular phenotype of estrogen receptor alpha-negative human breast tumors. Cancer Res. 2006;66(7):3903-11.

37. Rhodes DR, Yu J, Shanker K, Deshpande N, Varambally R, Ghosh D, et al. ONCOMINE: a cancer microarray database and integrated data-mining platform. Neoplasia. 2004;6(1):1-6.

38. Györffy B, Lanczky A, Eklund AC, Denkert C, Budczies J, Li Q, et al. An online survival analysis tool to rapidly assess the effect of 22,277 genes on breast cancer prognosis using microarray data of 1,809 patients. Breast Cancer Res Treat. 2010;123(3):725-31.

39. Castet A, Herledan A, Bonnet S, Jalaguier S, Vanacker JM, Cavailles V. Receptor-interacting protein 140 differentially regulates estrogen receptorrelated receptor transactivation depending on target genes. Mol Endocrinol. 2006;20(5):1035-47.

40. Deblois $\mathrm{G}$, Hall J, Perry M, Laganière J, Ghahremani M, Park M, et al. Genome-wide identification of direct target genes implicates estrogenrelated receptor alpha as a determinant of breast cancer heterogeneity. Cancer Res. 2009;69(15):6149-57.

41. Chang J, Clark GM, Allred DC, Mohsin S, Chamness G, Elledge RM. Survival of patients with metastatic breast carcinoma: importance of prognostic markers of the primary tumor. Cancer. 2003;97(3):545-53.

42. Desmedt C, Piette F, Loi S, Wang Y, Lallemand F, Haibe-Kains B, et al. Strong time dependence of the 76-gene prognostic signature for node-negative breast cancer patients in the TRANSBIG multicenter independent validation series. Clin Cancer Res. 2007;13(11):3207-14.

43. Subramanian A, Tamayo P, Mootha VK, Mukherjee S, Ebert BL, Gillette MA, et al. Gene set enrichment analysis: a knowledge-based approach for interpreting genome-wide expression profiles. Proc Natl Acad Sci U S A. 2005;102(43):15545-50.

44. Wang J, Duncan D, Shi Z, Zhang B. WEB-based GEne SeT AnaLysis Toolkit (WebGestalt): update 2013. Nucleic Acids Res. 2013;41(Web Server issue):W77-83.

45. Sun Y, Du C, Wang B, Zhang Y, Liu X, Ren G. Up-regulation of eEF1A2 promotes proliferation and inhibits apoptosis in prostate cancer. Biochem Biophys Res Commun. 2014;450(1):1-6.

46. Li Z, Qi CF, Shin DM, Zingone A, Newbery HJ, Kovalchuk AL, et al. Eef1a2 promotes cell growth, inhibits apoptosis and activates JAK/STAT and AKT signaling in mouse plasmacytomas. PLoS One. 2010;5(5):e10755.

47. Sun Y, Wong N, Guan Y, Salamanca CM, Cheng JC, Lee JM, et al. The eukaryotic translation elongation factor eEF1A2 induces neoplastic 
properties and mediates tumorigenic effects of ZNF217 in precursor cells of human ovarian carcinomas. Int J Cancer. 2008;123(8):1761-9.

48. Schubert A, Grimm S. Cyclophilin D, a component of the permeability transition-pore, is an apoptosis repressor. Cancer Res. 2004;64(1):85-93.

49. Eliseev RA, Malecki J, Lester T, Zhang Y, Humphrey J, Gunter TE. Cyclophilin D interacts with $\mathrm{BCl} 2$ and exerts an anti-apoptotic effect. J Biol Chem. 2009;284(15):9692-9.

50. Lee J, Kim SS. Current implications of cyclophilins in human cancers. J Exp Clin Cancer Res. 2010;29:97.

51. Riggins RB. The $\mathrm{pERK}$ of being a target: Kinase regulation of the orphan nuclear receptor ERRY. Receptors Clin Invest. 2014;1(5):253-7.

\section{Submit your next manuscript to BioMed Central} and take full advantage of:

- Convenient online submission

- Thorough peer review

- No space constraints or color figure charges

- Immediate publication on acceptance

- Inclusion in PubMed, CAS, Scopus and Google Scholar

- Research which is freely available for redistribution 